\title{
Prevalence and association of adverse pregnancy outcomes in pregnant women with abnormal levels of serum markers in the first trimester of pregnancy at Tehran Nasl-Omid Center in 2012-2016
}

\author{
Maryamsadat Mirazimi ${ }^{1}$, Fataneh Zonoozi ${ }^{2}$, Saiedreza Ghaffari ${ }^{3}$, Vahide Kazemi Majdabadi ${ }^{4}$ \\ ${ }^{I}$ Obstetrician and Gynecologist, Iran University of Medical Sciences, Tehran, Iran \\ ${ }^{2}$ Assistant Professor, Obstetrician and gynecologist, Iran University of Medical Sciences, Tehran, Iran \\ ${ }^{3}$ Department of Genetics, Nasl-Omid Laboratory, Tehran, Iran \\ ${ }^{4}$ General Surgeon, Iran University of Medical Sciences, Tehran, Iran
}

\begin{abstract}
Background: Due to the role of the markers of the first trimester of pregnancy in the adverse pregnancy outcomes and the inadequacy of studies conducted in Iran, in this study the frequency and relationship between adverse pregnancy outcomes in mothers with abnormal PAPP-A and free $\beta$ HCG values were investigated.

Materials and methods: In this cross- sectional study, 501 pregnant women referred to Nasl-Omid Laboratory in Tehran between 2012 and 2016 were studied. Demographic data, medical history and serum values of PAPP-A and free $B-\mathrm{HCG}$ of pregnant women were collected from their medical record or via telephone interview. Cut-off of the markers was considered as $0.4 \mathrm{MOM}$.

Results: A total of 501 pregnant women with a mean age of $29.14 \pm 24.4$ years and a gestational age of $37.8 \pm 1.67$ weeks were studied. $37.9 \%$ of pregnant women had abnormal levels of markers. In NT sonography report, subchorionic hematomas were reported in $17.2 \%$ of subjects. A significant relationship was found between maternal diabetes and hypertension and preterm delivery with PAPP-A $(\mathrm{p}<0.001$ and $\mathrm{p}=0.02$, respectively). There was also a significant relationship between subchorionic hematoma, preterm delivery and fetal death with free $\beta \mathrm{HCG}(\mathrm{p}=0.02, \mathrm{p}=0.02$ and $\mathrm{p}=0.009$, respectively).

Conclusion: Diabetes, high blood pressure, and preterm labor are related to PAPP-A, and subchorionic hematoma, preterm labor, and fetal death are associated with free B-HCG.

Keywords: Serum PAPP-A, Free Beta HCG, Pregnancy outcomes.

Cited as: Mirazimi M, Zonoozi F, Ghaffari SR, Kazemi Majdabadi V. Prevalence and association of adverse pregnancy outcomes in pregnant women with abnormal levels of serum markers in the first trimester of pregnancy at Tehran Nasl-Omid Center in 20122016. Medical Science Journal of IslamicJournal of Islamic Azad University, Tehran Medical Branch 2020; 30(3): 313-319.
\end{abstract}

Correspondence to: Maryam sadat Mirazimi

Tel: +989132942799

E-mail: Mymirazimi63@gmail.com

ORCID ID: 0000-0002-8721-927x

Received: 28 Jul 2019; Accepted: 28 Aug 2019 
مجله علوم يزشكى دانشگاه آزاد اسلامى

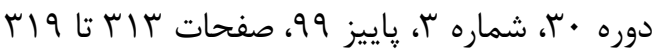

\section{بررسى فراوانى و ارتباط ييامدهاى نامطلوب باردارى در خانمهاى باردار با مقادير غيرطبيعى ماركرهاى سرمى سه ماهه اول باردارى در مركز نسل اميد تهران در

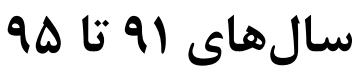

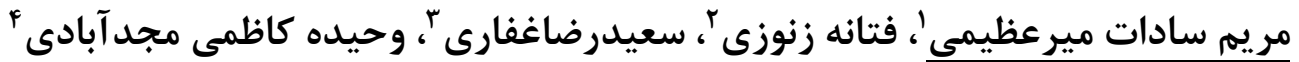

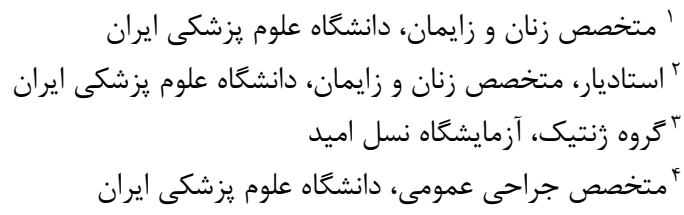

جكکبده

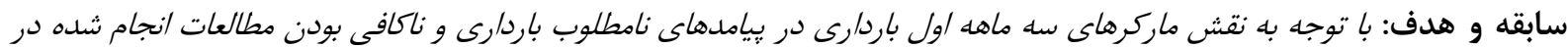

ايران، در/ين مطالعه فراوانى و/رتباط يِامدهاى نامطلوب باردارى در مادران با مقادير غيرطبيعى PAPP-A و free BHCG بررسى شل.

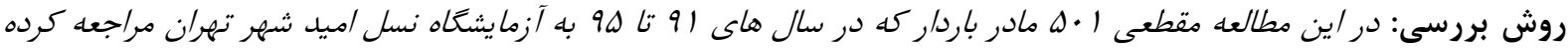

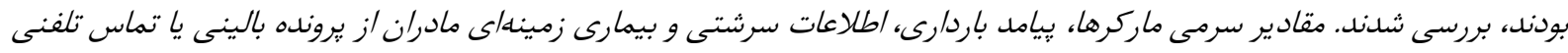

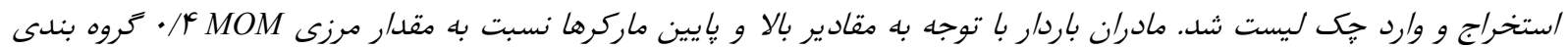

شلد.

يافته ها: تعد/د ا • D مادر بارد/ر با ميانكين سنى مادران باردار سطح غير نرمال ماركرها را داشتند. دركز/رش سونوكر/فى NT، IV/T درصد هماتوم ساب كوريونيك كز/رش شد. /رتباط

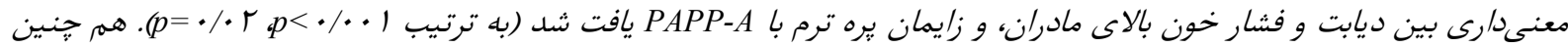

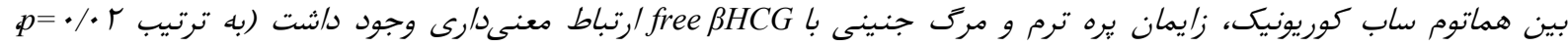
. $p=\cdot \cdot \cdot 9, p=\cdot 1 \cdot r$ نتيجه كيرى: ديابت، فشار خون بالا و زايمان بره ترم با PAPP-A و هماتوم ساب كوريونيك، زايمان يره ترم و مرك جنينى با free عار ارتباط دارند. وازَّان كليدى: free $\beta H C G$ ، PAPP-A بيامدهاى بارد/رى.

free $\beta$ HCG (beta human chorionic سـرم مـادر و (protein A مقدمه

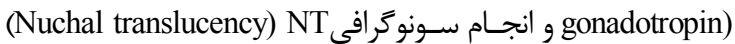
اشــاره كـرد كـهـ بــه منظـــور شناســايى ســندروم داون و سـاير آنايلوئيدىهاى جنينى انجام مىشوند (1).

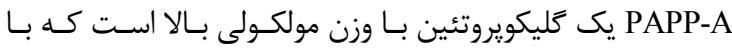
IGFBP4 (Insulin-like عملكرد يروتئازى خود بصورت طبيعى به growth factor-binding protein 4)
از غربالكرىهاى مهلم سه ماهــه اول بــاردارى مـى تـوان بـهـ انـدازه

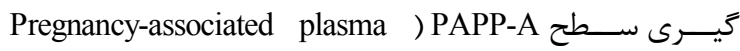

ادرس نويسنده مسئول: تهران، دانشكاه علوم يزشكى ايران، دكتر مريم سادات ميرعظيمى : إنس (email: : Mymirazimi63@gmail.com) ORCID ID: 0000-0002-8721-927x تاريخ دريافت مقاله: \$N/0/9 تاريخ بذيرش مقاله: 9N/9/9 
خصوص هماتوم ساب كوريونيــ را در مـادران بـاردار بــا مقـادير غيرطبيعى ماركرهاى سرمى سه ماهه اول باردارى تعيين كنيم.

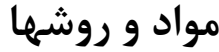

در مطالعه مقطعى حاضر كه از فروردين سال اجوسا تا بايان سـال

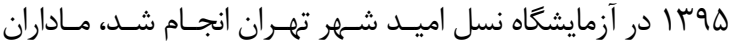

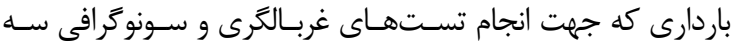
ماهه اول مراجعه كردند و معيارهاى ورود و خروج را دارا بودند، بــهـ روش نمونه كيرى سرشمارى انتخاب شدند.

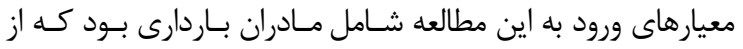

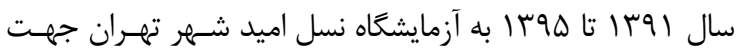

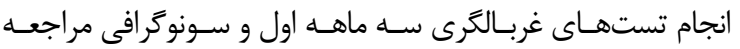

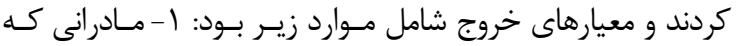

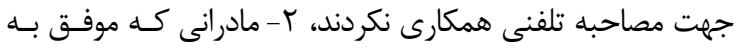

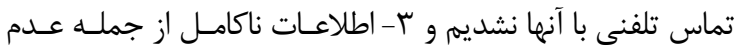

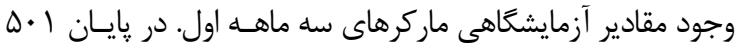
مادر باردار وارد مطالعه شدند.

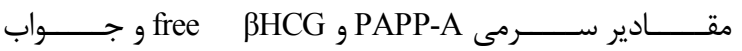
سـونوكرافىNuchal translucency (NT) از روى يرونــده بيمـاران

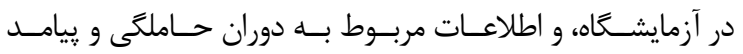

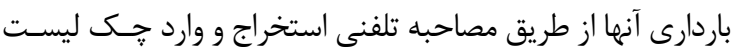

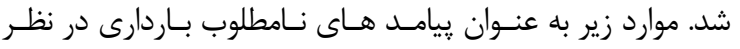

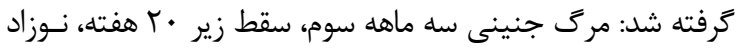

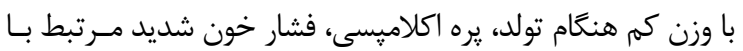

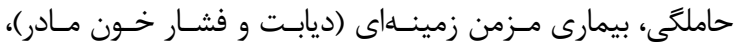

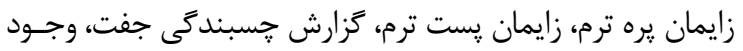

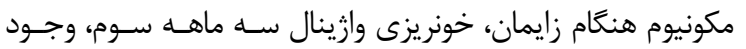
هماتوم هاى جفت در سونوكرافى سه ماهـ اول (از جملـه همـاتوم ساب كوريونيك). ساير اطلاعات جمع آورى شده در جـى ليكت ليست شامل نمايـهـ تـوده

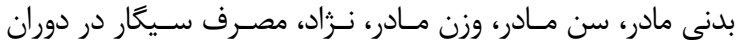

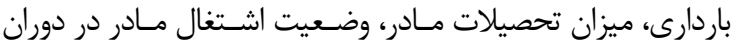

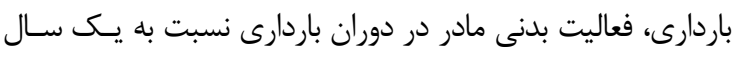

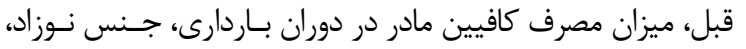

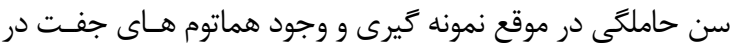
سونو رافى سه ماهه اول بود.

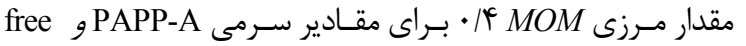

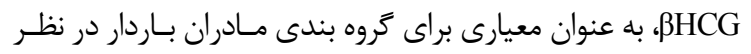

كرفته شد (9).
ترتيب تجزيه اين بروتئين تسهيل مسىشـود و free IGF حاصـل

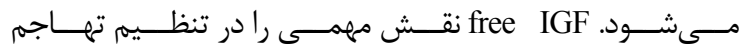
تروفوبلاستهاى جفتى به دسيدوا بازى مى كند. در حساملكى نرمـال

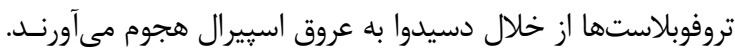

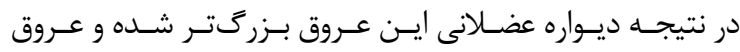

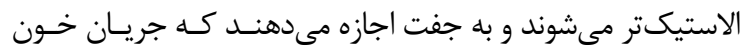
بيشترى را در خود جاى دهند (Гا). بنابر اين مقادير سـرمى يـايين

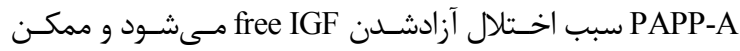

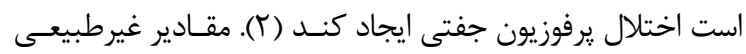

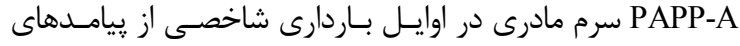

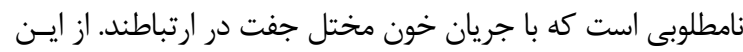

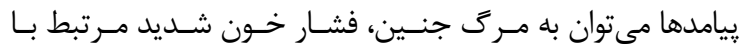

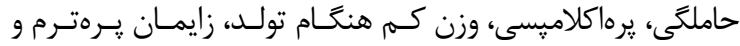

هماتوم ساب كوريونيك اشاره كرد (ه-").

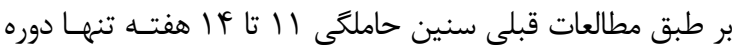

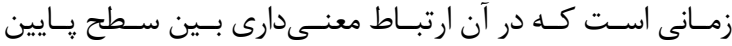

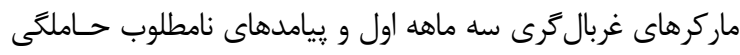

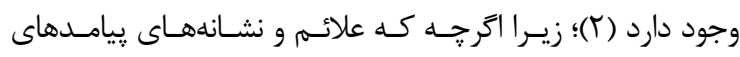

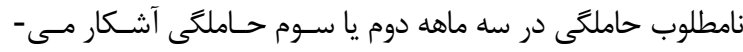

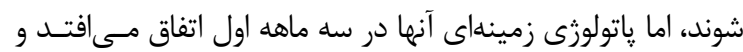

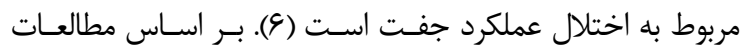

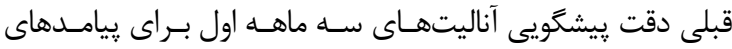

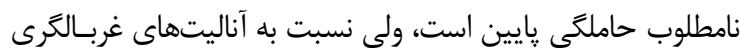
سه ماهه دوم دقت بسيار بيشترى دارد (؟). ارتباط مقادير غيرطبيعى بيوماركرهاى سه ماهه اول باردارى مثلـ

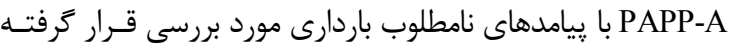

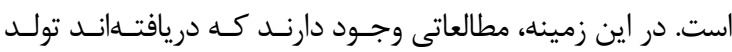

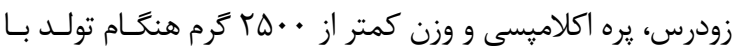

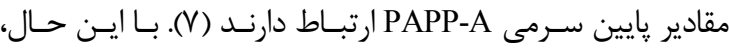

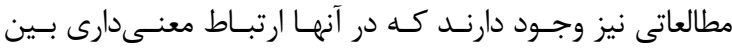

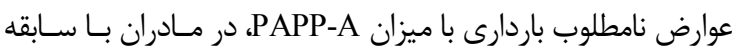

PAPP-A

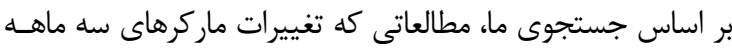

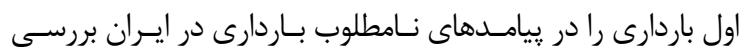

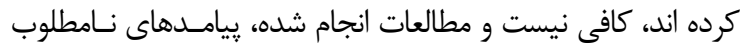

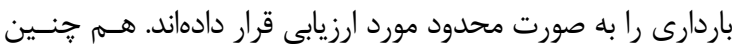

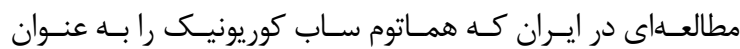

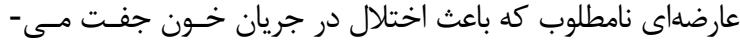

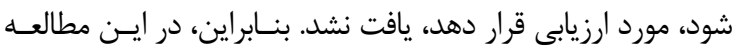

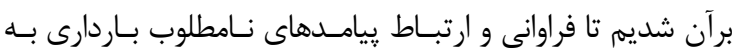




\begin{tabular}{|c|c|c|c|c|c|}
\hline p-value & مجموع & PAPP-A & نرمال PAPP-A & بالا PAPP-A & \\
\hline \multirow[t]{3}{*}{.$/ 9$} & $f \mid \Delta(1 \cdots)$ & $Y^{F}(\Delta / \Lambda)$ & rYG $(\Lambda r / F)$ & $F \Delta(1 \cdot / \Lambda)^{*}$ & هماتوم ساب كوريونيك منفى \\
\hline & $\wedge \&(1 \cdot \cdot)$ & $\varphi(V)$ & $V I(\Lambda T / \varphi)$ & $9(1 \cdot / \Delta)$ & هماتوم ساب كوريونيك مثبت \\
\hline & $0 \cdot 1(1 \cdot \cdot)$ & $r \cdot(\varphi)$ & Fiv $(\lambda r / r)$ & $\Delta F(1 \cdot / \Lambda)$ & مجموع \\
\hline
\end{tabular}

جدول r. ارتباط هماتوم ساب كوريونيك با سطح free BHCG مادران باردار

\begin{tabular}{|c|c|c|c|c|c|}
\hline p-value & مجموع & free $\beta H C G$ & نرمال free $\beta H C G$ & بالا free $\beta H C G$ & \\
\hline \multirow[t]{3}{*}{.1 .4} & $f \backslash \Delta(1 \cdots)$ & $9 \vee(\mid 9 / 1)$ & $r / f(V \Delta / V)$ & $r F(N / r)^{*}$ & هماتوم ساب كوريونيك منفى \\
\hline & $\wedge \varphi(1 \cdot \cdot)$ & $r \mu(Y G / V)$ & $\Delta r(\xi) / \varphi)$ & $1 \cdot(11 / 9)$ & هماتوم ساب كوريونيك مثبت \\
\hline & $0 \cdot 1(1 \cdot \cdot)$ & $q \cdot(1 \wedge)$ & TSV (VT/V) & $\operatorname{Ff}(\mathrm{N} / \mathrm{A})$ & مجموع \\
\hline
\end{tabular}

درصد از مادران در محدوده Q/ •-••، در س/

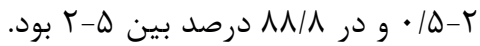

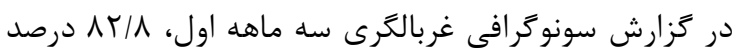

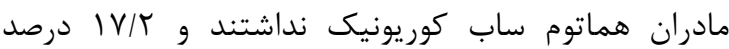
هماتوم ساب كوريونيك داشتند.

بين سن مادر با ميزان PAPP-A و

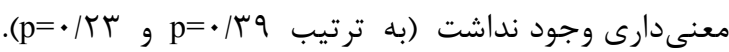

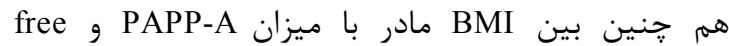
BHCG

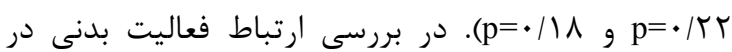
دوران باردارى نسبت به يك سال قبل مادر با ميزان free BHCG PAPP-A

$$
\text { (به ترتيب p=/ }
$$

بين بيمارى زمينهاى مادر با ميزان PAPP-A ارتباط معنى

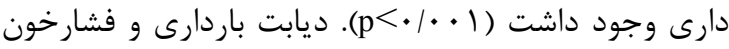
مزمن با low PAPP-A از نظر آمارى ارتباط معنى دارى داشتند، ولى با ميزان free $\beta$ ارتباط معنى دارى وجود اردي

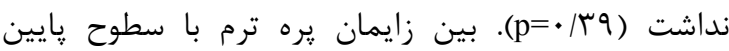
PAPP-A

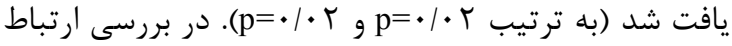

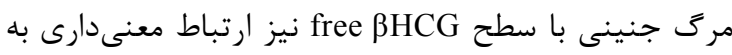

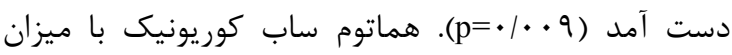

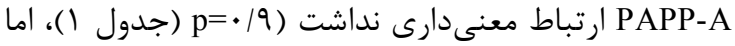

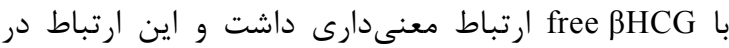
مشهود بود (row free $\beta \mathrm{HCG}$
دادهها با نرمافزار آمارى SPSS V. 23 تحليل آمارى شــند. نتـايج حاصله براى متغيرهاى كمى به صورت ميـانخين و انحـراف معيـار

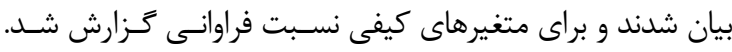

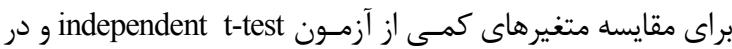

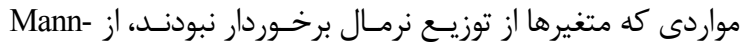
Whitney U test تسـ Fisher's Exact test و تحليـل شـــن chi-square

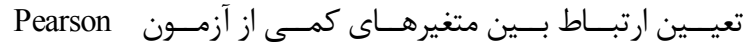

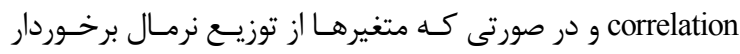

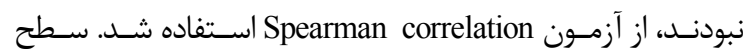

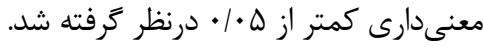

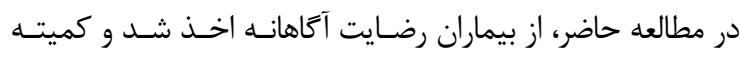

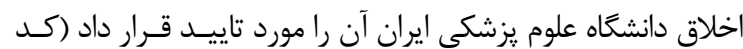
اخلاق: IR.IUMS.REC 1395.9211290018.

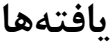

در اين مطالعه 1.0 مادر باردار با ميانكَين (و انحراف معيار) سنى مطالعه شدند. ميانخين (و انحراف معيار) BMI مادران برابر

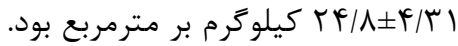
و free $\beta H C G$ و PAPP-A AY/1

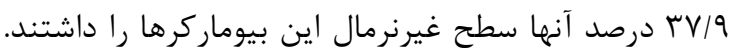

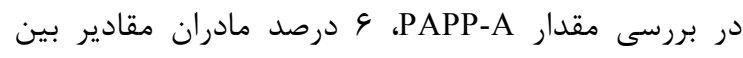

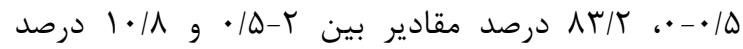

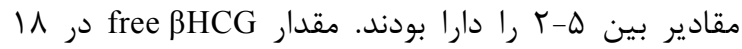


نتايج همراستا با ديكر مطالعات موجود در اين زمينه است كه

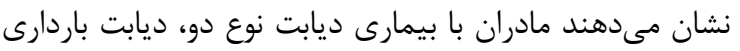

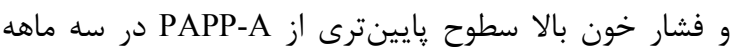

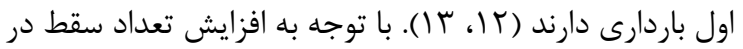

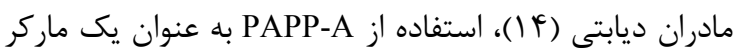

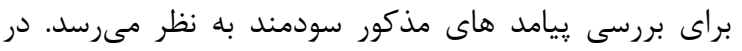

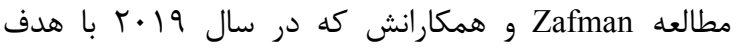

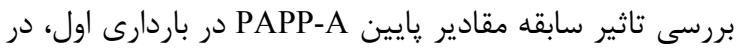

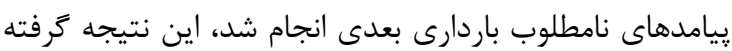

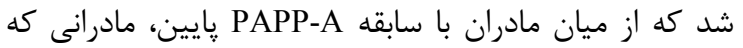

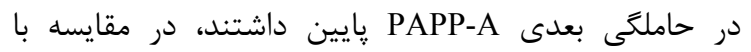

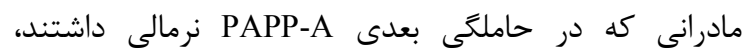
بيامدهاى نامطلوب باردارى مشابهى را بروز دادند (^).

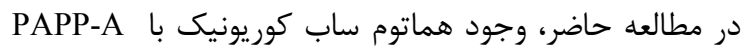

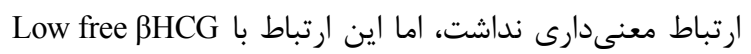

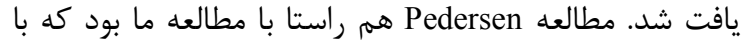

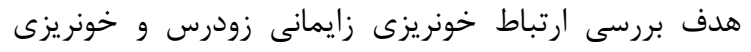

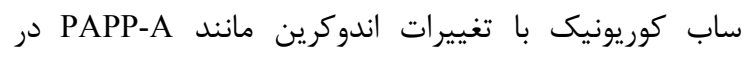

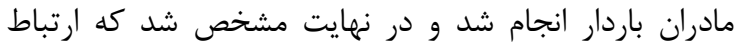
معنىدارى بين خونريزى ساب كوريونيك و سطح سرمى ادرى PAPP-A در بررسى ارتباط بين وجود هماتوم ساب كوريونيك و مرى

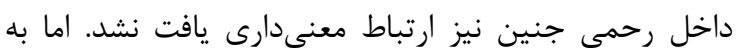

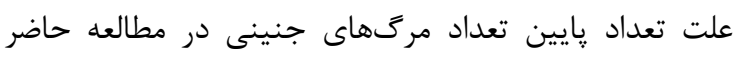

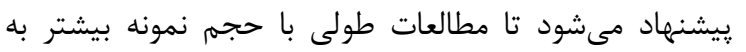

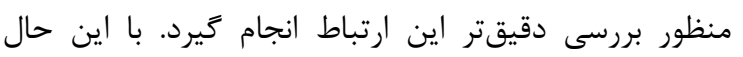

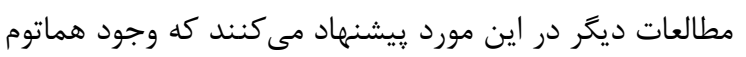

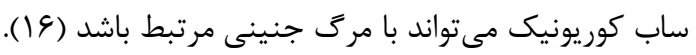

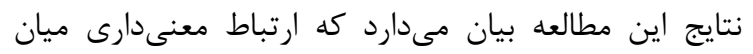

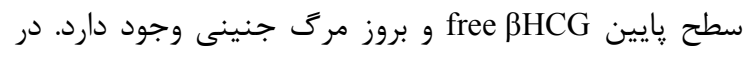

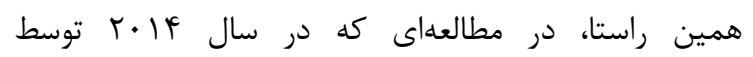
Valburena

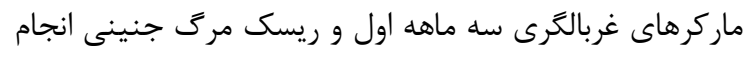

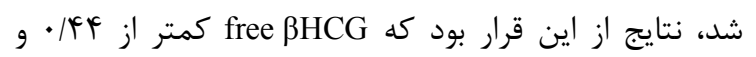
SAPP-A

$$
\text { جنينى است (IV) ( د) }
$$

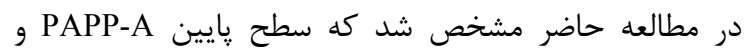

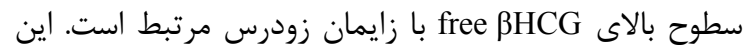

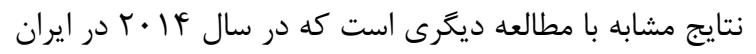

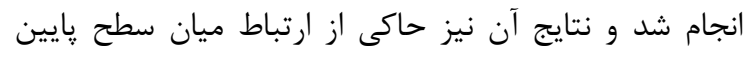

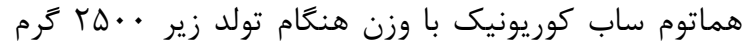

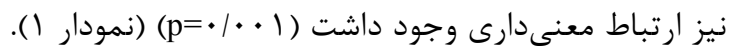

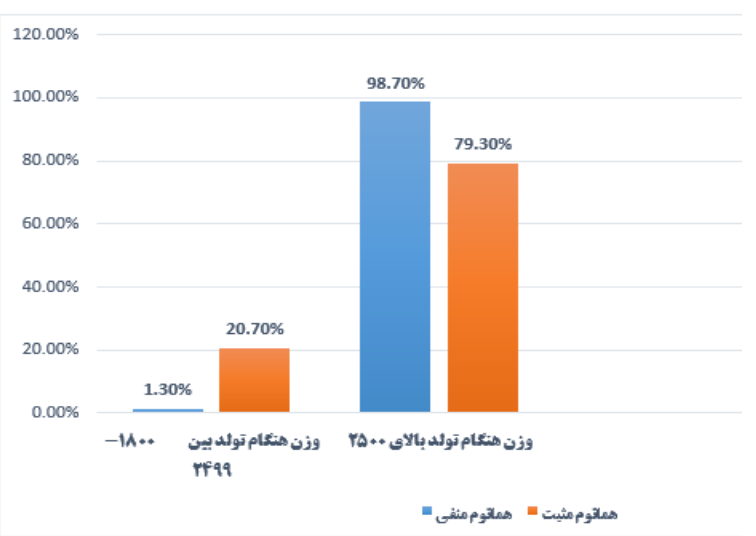

نمودار ا.ارتباط هماتوم ساب كوريونيك و وزن موقع تولد بالاى

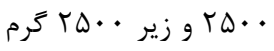

\section{بحث}

در مطالعه حاضر، TV/9 د درصد از مادران باردار سطح غيرنرمال

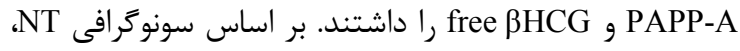
IV/T

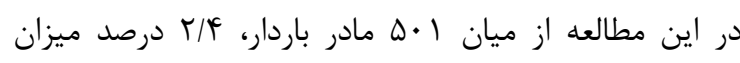
پايين داشتند. در مقايسه با مطالعات مشابه، Kaijomaa

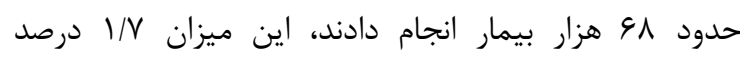

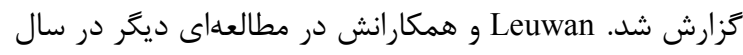

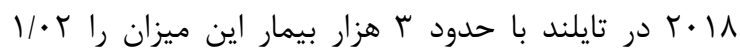

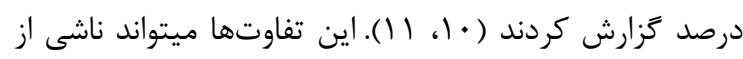

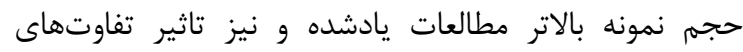
نزادى در سطح PAPP-A باشد.

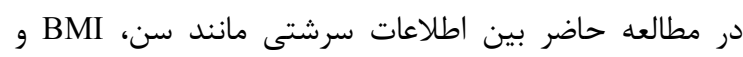

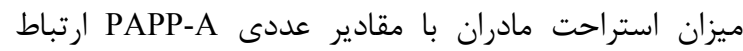

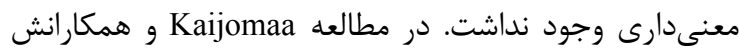

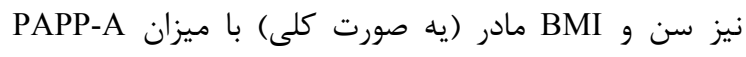

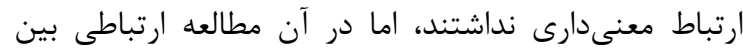

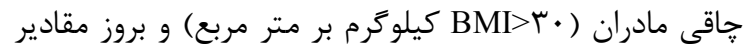

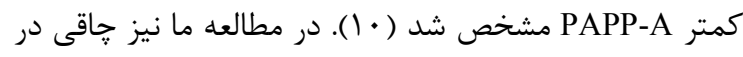

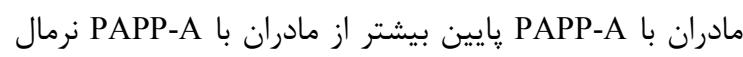

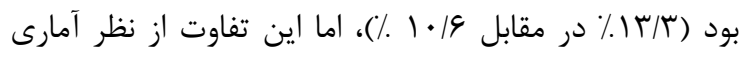

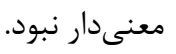
براساس نتايج مطالعه ما، بين بيمارى زمينهاى مادر (ديابت و فشار خون) و PAPP-A ارتباط معنىدارى وجود داشت. اين بن بناين 


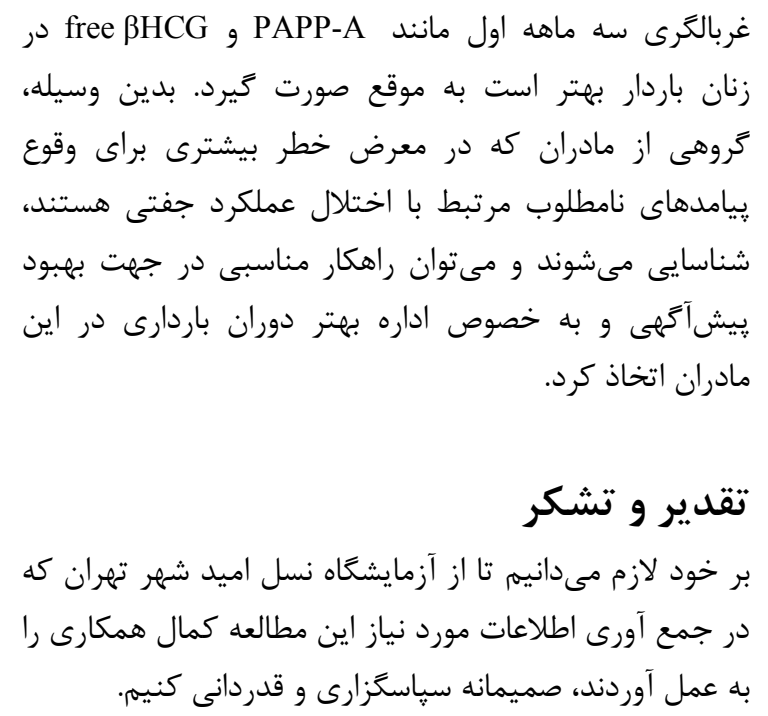

\section{تقدير و تشكر}

بر خود لازم مىدانيم تا از آزمايشعاه نسل اميد شهر تهران كه

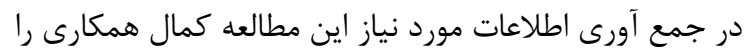
به عمل آوردند، صميمانه سياسگزارى و قدردانى كنيم.

PAPP-A در سه ماهه اول جنينى با زايمان زودرس بود (1). اما مطالعات ديخرى در اين زمينه، وجود ارتباط ميان سطح

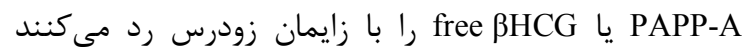
(19) كه احتمالا به علت تفاوت حجم نمونه و نوع مطالعات انجام شده با مطالعه حاضر است. از جمله محدوديتهاى اين مطالعه عدم بررسى همه ريسك إندام

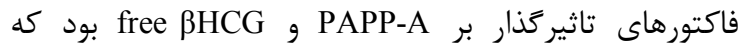

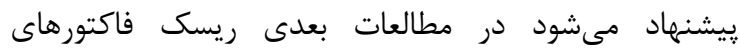
بيشترى لحاظ شوند تا نتايج دقيقترى به دست آيد.

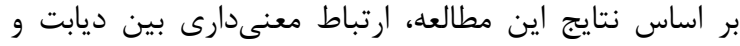

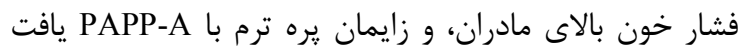

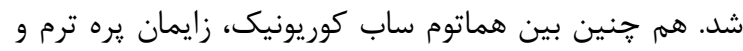
مرى جنينى با free $\beta$ ارتباط معنى دارى وجود داشت. بنابراين به نظر مىرسد اندازه گيرى سطح ماركرهاى سرمى

\section{REFERENCES}

1. Gupta S, Goyal M, Verma D, Sharma A, Bharadwaj N, Kabra M, et al. Adverse pregnancy outcome in patients with low pregnancy-associated plasma protein-A: The Indian Experience. J Obstet Gynaecol Res 2015; 8: 1003-1008.

2. Spencer CA, Allen VM, Flowerdew G, Dooley K, Dodds L. Low levels of maternal serum PAPP-A in early pregnancy and the risk of adverse outcomes. Prenatal diag 2008; 28: 1029-1036.

3. Cunningham FG, Leveno KJ, Bloom SL, Hauth JC, Rouse DJ, Spong CY. Fetal growth disorders. In: Cunningham FG, Leveno KJ, Bloom SL, at al, Eds. Williams obstetrics. 23rd Ed. New York: McGrow-Hill; 2010. P.842-858.

4. D'Antonio F, Rijo C, Thilaganathan B. Association between first- trimester maternal serum pregnancy- associated plasma protein- A and obstetric complications. Prenat Diagn 2013;33:839-847.

5. Spencer K, Cowans NJ, Nicolaides KH. Low levels of maternal serum PAPP-A in the first trimester and the risk of pre- eclampsia. Prenat Diagn 2008;28:7-10.

6. Zhong Y, Zhu F, Ding Y, Serum screening in first trimester to predict pre-eclampsia, small for gestational age and preterm delivery: systematic review and meta-analysis. BMC Pregnancy ChildB 2015; 15: 1-10.

7. Livrinova V, Petrov I, Samardziski I, Jovanovska V, Boshku AA, Todorovska I, et al. Clinical Importance of Low Level of PAPP-A in First Trimester of Pregnancy-An Obstetrical Dilemma in Chromosomally Normal Fetus. Open Access Maced J Med Sci 2019;7:1475.

8. Zafman KB, Getrajdman CS, Arnold MK, Stone JL. Are women with a history of low PAPP-A at risk for adverse perinatal outcomes in a subsequent pregnancy? American J Perinatol 2019;36:647-52.

9. Hoffman BL, Schorge JO, Bradshaw KD, Halvorson LM, Schaffer JI, Corton MM, Eds. Williams gynecology. New York: McGraw-Hill Education; 2019

10. Kaijomaa M, Rahkonen L, Ulander VM, Hamalainen E, Alfthan H, Markkanen H, et al. Low maternal pregnancyassociated plasma protein A during the first trimester of pregnancy and pregnancy outcomes. Int J Gynaecol Obstet 2017; 136:76-82.

11. Luewan S, Teja-Intr M, Sirichotiyakul S, Tongsong T. Low maternal serum pregnancy-associated plasma protein-A as a risk factor of preeclampsia. Singapore Med J 2018;59:55-59.

12. Wells G, Bleicher K, Han X, McShane M, Chan YF, Bartlett A, et al. Maternal diabetes, large-for-gestational-age births, and first trimester pregnancy-associated plasma protein-A. J Clin Endocrinol Metab 2015;100:2372-9.

13. Meloni P, D'Angeli I, Piazze J, Cerekya A, Simari T, Pala A, et al. First trimester PAPP-A levels associated with early prediction of pregnancy induced hypertension. Hypertens Pregnancy 2009;28:361-8.

14. Asnafi N HAM, Javan Sh, Taheri B, Baleghi M. Comparison of pregnancy outcomes in diabetic pregnant women with control group. Journal of Babol University Of Medical Sciences 2011;13:52-7. [In Persian] 
15. Pedersen JF, Ruge S, Sørensen S. Serum levels of hPL, PAPP-A and PP14 in patients with early pregnancy bleeding and subchorionic hemorrhage. Acta Obstetricia et Gynecologica Scandinavica 1995;74:30-2

16. Şükür YE, Göç G, Köse O. The effects of subchorionic hematoma on pregnancy outcome in patients with threatened abortion. J Turk Ger Gynecol Assoc 2014;15:239-42.

17. Valbuena H, Ramis J, Sagala J, Sanchez MA, Aulesa C. First-trimester screening biochemical markers (free betasubunit human chorionic gonadotropin, pregnancy-associated plasma protein-A) and risk of early fetal loss. J Gynaecol Obstet Res 2015;41:69-76.

18. Mohamad Jafari R, Taghvai Maasomi M, Najafian M, Saadati N. Preterm delivery in women with low PAPP-A at first trimester screening. Tehran Univ Med J 2014;72:457-62. [In Persian]

19. Morssink LP, Kornman LH, Hallahan TW, Kloosterman MD, Beekhuis JR, de Wolf BT, et al. Maternal serum levels of free beta-hCG and PAPP-A in the first trimester of pregnancy are not associated with subsequent fetal growth retardation or preterm delivery. Prenatal Diagnosis 1998;18:147-52. 